Uşak Üniversitesi Sosyal Bilimler Dergisi

$2015,8 / 1$

\title{
Romantizm, Fantazya ve Rasyonalite: Evlilik Dergileri ve Evlilik Web Siteleri
}

Ayşe ÇATALCALI*

Özet

"Romantizm, Rasyonalite ve Fantazya" olguları temel alınarak, kapitalizm tarafından desteklenen evlilik endüstrileri, günümüzün evlilik kurumunu yeniden inşa etmektedir.

Evlilik endüstrileri, özellikle de romantik imajinasyon yoluyla, evlilik kurumunu ve gelin kimliğini metalaştırmakta ve pazara hazırlamaktadır. Kapitalist pazar payı içinde medya şirketlerinin de ortaklığı vardır. Tüketimi hızlandıran medya, kültürden kültüre evlilik seremonileri değişse de, evlilik organizasyonları çerçevesinde yeni bir "evlilik tüketim kültürü" oluşturmaktadır. Tüketim söz konusu olduğunda, kapitalizm aracı olan evlilik dergileri de, esneklik ve işbirliği içinde yeni "evlilik büyüsünü" devreye sokmaktadirlar.

Günümüzde Evlilik dergileri, evlilik için "alışveriş dură̆ı" görevi üstlenmektedir. Erkek, kadın kimliğinin geleneksellik içinde örüntülenerek çocukluk sürecinde oluşturulan "gelin/prenses/beyaz melek" olmak simülasyonu, tüketim kültürü içinde hareket ettirmektedirler. Geleneksel rol modelleri içinde tanımlanan gelin kimliği tüketim kültürü ile örüntülendirilmektedir. Çocukluk evresinde masallarda tanitılan gelin/prenses/ beyaz melek sembolleştirmeleriyle gelin kimliği simülaşyon ortamına çekilmektedir. Kadın kimliği, "hayal dünyası" ve "rasyonalite" içinde yapılandırılmaktadır.

Araştırmada, evlilik dergileri ve evlilik üzerine kurulu web sitelerinde, tüketicilere nasıl seslenildiği, hangi stratejiler kullanıldığı, hangi evlilik tiplerinin ticarileştirildiği, gelin kimliğinin inşası ve "farklı ve ayırıcı" yanıyla evlilik projesinin yönetimi incelenmektedir. Bu doğrultuda, "Perfect Wedding" ve "Bride's" dergilerinin içerikleri, http://www.mutlugelin.com ve http://www.gelinlik.org" adlı web sitesi içerikleri niteliksel analiz yöntemi ile ele alınmaktadır.

Anahtar Kelimeler: Evlilik, Evlilik Endüstrisi, Kadın Kimliği, Evlilik Dergileri.

\footnotetext{
*Yrd. Doç. Dr., Ege Üniversitesi İletişim Fakültesi
} 
A. ÇATALCALI 38

\title{
Romanticism, Fantasy and Rationality: A Research on Magazines and Wedding Web Sites
}

\begin{abstract}
The marriage industries which are supported by capitalism, are rebuilding made over the the today's institution of marriage based on romanticism, rationality and fantasy facts ".

The these industries, are commoditized the identities of the bride and groom through the romantic imaginations and they are prepared for marketing. Media companies also have marketshare in global capitalist markets. The media which is increased the consumption of goods and services, are create new consumer culture of marriage within the scope of organizing marriage seromonies even though they are changing from culture to culture. The mariage magazines which are involved marriage culture are popularized "magic of marriage" myth, created by patterns of flexibility and solidarity in the consumer culture.

Nowadays, the marriage magazines are perform as a stop shopping. Described bride identity in the traditional role models is knited with consumer culture. Bride identities are incorporated into simulation environment via sembolization of white angels/princes which are familarized in child stage. Woman identity is constructed via rationalisings in fantasy world.

In this study is investigated which strategies are used, how announced to consumer, consturuction of bride identity, which marriages are commodification and the management of marriage projects and their distinctive and different ways in marriage magazines and marriage web cites . So that the contents of "Perfect Wedding" ve "Bride's" magazines and http://www.mutlugelin.com ve http://www.gelinlik.org" web cites are analysed by the method of qulitative content analysis.
\end{abstract}

Key Words: Marriage, Marriage Industries, Women Identities, Marrige Magazines.

\section{Giriş}

Genç kızlıkta hayal dünyası ve fantazya ile beslenen ve pekiştirilen, sıklıkla kadın fantezisi olarak görülen evlilik, günümüzde tüketimi işaret etmektedir. Zira ritüeller, seremoniler, pratikler, evlilik için düşünülen her detay, tüketim için ideal bir araç konumundadır. Masallar içerisinde "prenses-prens" ilişkisiyle başlayan, "beyaz atlı prensin" beklenilmesiyle 
Sosyal Bilimler Dergisi 39

devam eden ve toplumsal yapıya bağlı olarak "ideal" olan eşin arandığı tüm yaş dönemlerinde, "evlilik miti" geliştirilmekte ve albenili hale getirilmektedir. Söz konusu albeni TV formatlarıyla, kitle iletişim araçlarının tüm yelpazesi içinde pazara hizmet ederek desteklenmekte ve küresel sermayenin yararına hareket sağlanmaktadır. Adeta yaratılan bir evlilik endüstrisi oluşturulmakta ve tüketim programlanmaktadır.

Amerika'da Amerikan evlilik istatistiklerine göre, uluslararası evlilik profesyonelleri birliği AFWPI.com'da evlilik pazarının 2005'te 30 milyon dolar kazandırdığını belirtilmektedir. Chrys Ingraham'ın "evlilik endüstrisi kompleksi" (Wedding industrial complex) adlı çalışmasında bu endüstrinin büyük bir iş alanı olduğu ifade edilmektedir. Bu kompleksin içinde evlilik elbiseleri, fabrikaları, popüler filmler, seyahat endüstrisi, mücevher alanı, romantik müzik sektörü, vb. yer almaktadır. Böylelikle tüketim içinde evlilik düşleri, hazırlık boyutu-evlilik ve evlilik sonrası dönemleriyle bireylerin ödüllendirildikleri görülmektedir (Sgroi, 2006; 113).

Frankfurt Okulu'na göre, kültür endüstrisinin araçları olarak kabul edilen medyanın teknoloji ve ekonomik gücü elinde bulundurması, kapitalist düzenin devamlılığını gözetmektedir. Teorisyenler Adorno ve Horkheimer, medyanın ticari çıkarları doğrultusunda kitle kültürüne hakim olduğunu ve eğlence endüstrisi yoluyla da tüketim toplumunun yaratıldığını kabul etmektedirler (Küçükcan, 2002; 258).

Leslie Sklair (1998; 297, Akt: Denning, 2001, 354-355), kültürün pazar payını "tüketimin kültür ideolojisi" olarak vurgulamaktadır. Her ne kadar toplum yapılarına göre evlilikler şekillense de, "ideal evlilik" tipleri ve romantik müziklerin pazarlanması, ideolojinin yaygınlaşmasını sağlamaktadır. Küreselleşme ile birlikte ulus-ötesi hale gelen kültür alışverişinin, özellikle müzik ve film sektörünün aracılığıyla artırdığı gözlemlenirken, ulus kültürlere dâhil olan birçok müziğin küresel pazarda "uygun zamanda ve merkezin isteğine bağlı" olarak yer bulduğu, bu müziklerin bir pazar oluşturduğu, film içeriklerinde kullanımlarının veyahut film müziği olarak hatırlanmalarının, kültürel bir alışveriş oluşturduğu anlaşılmaktadır.

Eleştirel Kuramcılar, 'kültür endüstrilerini', kültürü, reklamı ve kitle iletişimi ile yeni toplumsal denetim biçimlerini, kapitalist toplumun yeni biçimlerine "riza üretmede" kullanan kapitalist modernitenin yeni biçimlenişinin merkezi bir parçası olarak görmeye başlamışlardır. Kültür endüstrilerinin bireyler üzerinde riza üreterek pasifize ettiği kabul edilmekte ve insanın davranışları, tutumları, düşünceleri ve eylemleri standart hale getirilerek, "tek boyutlu insan ve tek boyutlu toplum" meydana getirdiği vurgulanmaktadır. 
A. ÇATALCALI 40

Kapitalist Pazar içinde medyanın da pay ortaklığının olması nedeniyle, evlilik endüstrileri aracılığıyla, özellikle de romantik imajinasyon yoluyla, evlilik kurumunu metalaştırmakta ve pazara hazırlamaktadır. Tüketimi hızlandıran medya, evlilik organizasyonları çerçevesinde yeni bir evlilik ve tüketim kültürü oluşturmakta ve evlilik büyüsünü devreye sokmaktadır.

Bu çalışmada, evlilik endüstrilerinin ve organizasyonlarının aracısı olan kitle iletişim araçlarından dergiler ve web siteleri ele alınarak, "evlilik büyüsü"nün nasıl inşa edildiği araştırılmaktadır. "Farklılık ve ayırıcılık" yanıla evlilik projelerinin sunumlarının hangi rasyonel, romantik ve fantazyaya dayalı noktalar ile vurgu yapıldığına bakılmaktadır. Bu doğrultuda, "Perfect Wedding" ve "Bride's" dergilerinin içerikleri, http://www.mutlugelin.com ve http://www.gelinlik.org" adlı web sitesi içerikleri niteliksel analiz yöntemi ile ele alınmaktadır.

\subsection{Küreselleşme, Tüketim ve Evlilik Endüstrileri}

Baudrillard, Simmel, Marcuse, Bauman, Ritzer (1998), Featherstone (1996) vd. gibi birçok araştırma özellikle küreselleşme ve tüketim kültürü ilişkisi üzerinde durmakta ve tüketimin modern ve postmodern toplumların vazgeçilmezi olduğunda birleşmektedirler.

Modern insan, hayatını giderek daha az emek içinde üretimle, ama giderek daha fazla kendi ihtiyaçlarının ve refahının üretimi ve sürekli yenilemesiyle geçirmektedir. Modern insan tüketici potansiyelliklerinin ve kapasitelerinin tamamını seferber edecek şekilde kendini hazırlamak zorundadır. Eğer bunu unutursa kendine mutlu olma hakkına sahip olmadığı kibarca hatırlatılmaktadır (Baudrillard, 1997; 89).

Postmodern insan hayatında ise artık üretim göz ardı edilmekte ve tüketim vazgeçilmez bir unsur olarak adeta zihinlere enjekte edilmektedir. Birey bütün potansiyelini ve yetilerini tüketim uğruna harekete geçirmeye hazır durumdadır.

Tüketimciliğin uzandığı evrenler ise, alabildiğine çeşitli ve zengindir; mekanlar, eşyalar, giyim-kuşam, yeme-içme, tarih, coğrafya, beden, arzu, haz vs. gibi çok farklı dünyaları kapsamaktadır. Tüketimci stratejiler sayesinde, hemen her yaşam alanı, yok edilmeye, kolonize edilmeye açık bir av sahası halini almaktadır (Aytaç, 2006; 28). Tüketicinin dikkatini çeken her sembol veya semboller sistemi onu tüketime sürüklemektedir. Birey için göstergeler bir güdüm oluşturmaktadır. Öyle ki, dergilerin üzerinde oluşturulan gelin kimlikleri, "beyaz, masum, temiz ve güzel” göstergeleri doğrultusunda, kadın tüketicilere cazip gelebilmektedir. 
Sosyal Bilimler Dergisi 41

Baudrillard (1997; 89), tüketim toplumu kitabında; "gerçek ihtiyaçlar ile çağımızın yönlendirdiği sahte ihtiyaçlar arasındaki ayrımın ortadan kalktığı tüketim toplumunda tüketim mallarını satın almanın ve bunları sergilemenin toplumsal bir ayrıcalık ve prestij getirdiğine inanmaktadır. İnsan bu süreçte bir yandan kendini toplumsal olarak diğerlerinden ayırt ettiğine inanırken, diğer yandan da tüketim toplumuyla bütünleşmektedir. Dolayısıyla tüketmek birey için zorunluluğa dönüşmektedir. İnsani ilişkiler yerini maddelerle ilişkiye bırakmaktadır. Artık geçerli ahlak, tüketim etkinliğinin ta kendisidir" demektedir.

Baudrillard'ın simülark kavramı yani "gerçek bir toplum değil", "mış gibi yapılan" sembollerin ve imajların aldığı sanal gerçeklik durumunda ise, artık hipergerçeklik söz konusudur. Hiper-gerçeklik tekrar tekrar üretilmektedir. Örneğin, evlilik endüstrileri bu gerçeklik içinde tekrar ve tekrar evlilikleri ve gelin kimliklerini inşa etmektedirler. Kitle iletişim araçları aracılığıyla evlilik endüstrileri organizasyonlarına daha da yakınlaşan tüketiciler, "farklı ve ayırıcı" olan gelin olmak ve evlilik merasimlerini düzenlemek adına hiper-gerçekliğin içinde bilerek/bilmeyerek yer almaktadırlar. Yaratılan gelin ve evlilik stereotipi dolayısıyla zihinsel bilişsel haritalar yeniden ve yeniden şekillendirilmektedir. Özellikle eğlence sektöründe kullanılan stereo-gerçeklikler, "gerçeği", "sanal gerçeklikler" olarak sunmakta ve kitlelerin evlilik üzerine kültürlerini büyük ölçüde inşa etmektedirler. Stereo-gerçekliklerin, sadece görsel iletişim kanallarıyla veya internet(sanal ortam) üzerinden değil, çok eskiden beri yazılı iletişim araçları ile de kurulduğu söylenebilmektedir. Yazılı alanda dergilerin, bu gerçekliği stereotipler (kalıpyargılar) üzerinden, "çocuk, genç ve kadınerkek" kimliklerini kullanarak sağladıkları anlaşılmaktadır. Özellikle dergilerin, çocuk ve genç kitleye yönelik yaklaşımları dikkat çekicidir. Araştırmacı Mc Robbie (Frazer, 1987; 407-425), "Jackie" adlı dergi üzerinde yaptığ1 araştırmada, derginin tüketiciyi cezbetme yönünü incelemekte ve 4 nokta üzerinde durmaktadır;

“(...) Buna göre; Aşk Şifresi (Romans), 2. Özel Yaşam Şifresi (Ev), 3.

Moda ve Güzellik Şifresi, 4. Pop Müzik Şifresi" önemli hale gelmektedir.

Dergiler üzerinde özellikle "Aşk şifresi" yüceltilerek, aşkın herkes tarafından tadılması gerektiği belirtilmektedir. Aynı sebepler gerek dergiler gerekse de evlilik alışveriş sitelerinde, "herkes" evlenmelidir şeklinde vurgulanmakta ve ancak bir yandan ayırıcı, öte yandan da bütünleştirici yönlerine de dikkat çekilmektedir. Böylelikle her genç kız aşık olacak ve evlenecektir. Gerçek hayatta tam olarak aşkı bulabilmiş/tadabilmiş insan sayısı düşünüldügüünde, herkesin aşka kavuşmadığı açıtır. Ancak verilen 
mesajların bütünü, aşkı yakalamış ve mutlu evlilikler kurabilmiş olmanın organizasyonu üzerinedir. Stereo-gerçekliğe duyulan özlem öylesine büyüktür $\mathrm{ki}$, küresel pazarın tüketim metalarına dönüştürüldüğünden haberdar değillerdir.

Dergilerin aşk şifresinde, örneğin; tüketiciler(genç kız) için, zengin sevgili, ünlü sevgili, yakışıklı sevgili, sarışın-uzun boylu-iyi giyimli sevgili, esmer-kara kaş kara göz-maço sevgili, arabalı sevgili vb. kimlikleri öne çıkarılmaktadır. Oysa yaratılan stereotiplerin, okuyucu kitlenin içinde bulunduğu gerçekliklere çoğu zaman uymadığı bilinmektedir. Kısacası ünlü sevgili edinmek isteyen ünlü bir tüketici (okuyucu) sayısı son derece azdır. Böylesi bir durum, çoğunlukla birçok tüketicinin çizilen stereotiplerin dışında kaldığını göstermektedir. Tüketiciler çizilen stereo-gerçeklik içinde hareket ederken, özdeşim kurdukları sevgiliye, dolayısıyla gerçeğe ve "aşka" çok uzaktırlar.

Birçok dergide gençlerin aşık olabilecekleri sevgili prototipleri çizildikten sonra, aşkın ve ikili ilişkilerin sürdürülme yollarının zor ve kolay yanlarının ne olduğu, sorunlar karşısında nasıl mücadele edebilecekleri vb. anlatılmaktadır. Bu anlatımlar aracılığıyla, sorunların çözümü için, dergilerde çoğu zaman birtakım tüketim yolları önerilmektedir. Örneğin, küsülen sevgiliyle pahalı hediyeler alarak barışmak, karşı cinse güzel ve hoş görünmek için iyi kıyafetler giymek, süslenmek, güzel kokmak ve kozmetik ürünleri kullanmak vb. tavsiyeler verilmektedir. $\mathrm{Bu}$ durum, genç okuyucuların "aşk şifresi" üzerinden tüketim toplumuna hizmet eden bireyler olarak yönlendirilmelerini sağlamaktadır.

Özel Yaşam Şifresi de, okuyucuları ev yaşantısı içinde bırakmaktadır. Ancak ev yaşantısına ilişkin haberlerde, gerek evin dekorasyonu (tarz yaratan pahalı mobilyalar, bahçe tasarımı, 1şıklandırma, aksesuar, renk dokusu vb.) gerekse de sosyal çevresindeki bireylerin birbirleriyle kıyaslayacakları "gizli rekabet" duygusu vurgulanmaktadır. Her iki durumda da bireysel haz ele alınırken, geri planda bu hazzı destekleyen bir tüketim evreni olduğu ancak toplumsal olarak da özel yaşam şifresi üzerinden, bireyin kimlik edinme sürecini destekledikleri görülmektedir. Evlilik dergilerinde evlilik kadar ev tasarımı ve dekorasyonu önemli olmaktadır. Ev hazırlıklarının nasıl yürütüleceği, ev dekorasyonunun ipuçları ön plana çıkarılan konulardandır.

Moda ve Güzellik Şifresinde ise, dergiler de genç tüketicilerin modayı takip etme ve modaya göre giyinme, güzel olmanın önemli olduğu, güzel olmanın sırları, güzelliğin zayıflık ve iyi giyinme gibi unsurları taşıyarak elde edileceği yönünde bilgiler verilmektedir. Dergi içeriklerinde ön plana çıkarılan bu stereotipler, genç kızların belki de hiçbir zaman 
gidemeyecekleri güzellik salonları, alışveriş yapamayacakları pahalı mağazalarla dolu bir hayal dünyasına sürüklemektedir. Evlilik dergi ve web sitelerinde gezinmek de genç kızların nasıl bir gelin olmaları gerektiği yönünde moda bilgisini yüklemektedir.

Pop Müzik Şifresi de, gençlerin müzik dünyasındaki yaratılan eski ve yeni pop idollerine hayran kalmaları ve bunlarla gerek kıyafetleri, gerek söyledikleri sözler gerekse de yaşantı biçimleri ile özdeşim kurarak anlam dünyaları inşa edilmektedir. Böylelikle pop starlarıyla kurulan her özdeşim, onların ticari Pazarda hareket eden CD, poster, film, dergi afişi gibi birçok tüketim metasını kullanmaları, küresel müzik Pazarına hizmet etmelerini sağlamaktadır. Söz konusu idollerin evlilik organizasyonları ve evlilik sembolleri/göstergeleri, okuyucular için önemli hale dönüşmektedir.

\subsection{Evlilik Organizasyonları ve Beyaz Evlilikler}

Kitle iletişim araçlarının içeriklerinin ardalanında, toplumun gerek kültürel tektipleştirme gerek yurtsuzlaşma ve gerekse de bireylerin özdeşim noktaları bularak bağımlılı̆̆ı söz konusudur. Ekonomik, siyasal ve kültürel yönden giderek kendini hissettiren küreselleşme ve medyanın aracıllğ̆ıla, bu bağımlılık toplumları, belli melezlenmelere taşımakta ve araştırmacılar Salinas ve Paldan'a göre de toplumları, "kültürel türdeşliğe" itmektedir. Onlara göre, bütün dünya birbirine benzemektedir (1979, Akt: Tomlinson, 1999, 92).

Kültürel türdeşlik konusu evlilik endüstrilerinin ve evlilik organizasyonlarının da bir türdeşlik için de gelişmesini sağlamaktadır. Evlilik hazırlıkları içinde olan tüketicileri alışverişe yönlendiren ekonomik, psikolojik, sosyolojik vb. bir dizi değişkenden bahsetmek mümkün olmaktadır.

Evliliğe ilişkin sosyal unsurlar içerisinde "benzer bir deneyime sahip olan diğerleriyle iletişim kurmak" unsuru, evlilik alışverişleri sırasında tüketiciler için sık rastlanılan bir iletişim ağıdır. Özellikle alışveriş sırasında "pazarlık yapmanın vermiş olduğu haz" da bireylere cazip gelebilmektedir.

Alışveriş merkezlerinin, sadece bir şeyler satın alan, akılcı, ihtiyaçlarıyla sınırlı alışverişe yönelen rasyonel tüketicilere yönelik hizmet vermedikleri, aynı zamanda boş zaman geçirmek, vitrinleri seyretmek ve mekân içerisinde gezinmek isteyen boş zaman tüketicilerine yönelik de hizmetler verdikleri kabul edilmektedir. P. Falk ve C.Campbell için (1997; 12, Akt: Özcan, 2007; 47) alışveriş, genellikle kamusal alanda yapılan özel bir deneyimdir. Özellik ve sosyallik arasındaki bir yerde meydana gelmektedir. Aynı zamanda rasyonellik ve uyarılma ile haz sağlayan sosyal bir deneyim ve ihtiyaçları karşılayan zorunlu bir eylem şekli olma arasında yer alan, 
kendi içinde çelişkili, hem haz, hem de endişe veren, çabucak kabusa dönüşebilen lezzetli bir deneyimdir. Bu nedenledir ki, alışverişin, aydınlık olduğu kadar karanlık tarafı da vardır.

Zira arzulamanın bir yaşam onayı haline geldiği bir tüketim toplumunda, tüketmeye umudu olmayanlar ve hem de buna güçleri yetmeyenler için, arzulama etrafında dönmeleri ya da tüketime sadece büyü ve fanteziler içinde bakmaları söz konusudur (Belk vd. 2003; 347, Akt: Özcan, 2007; 49). Artık arzulama için sadece mekân gezmek gerekmemekte, sanal ortamlar üzerinden yürütülen tüketim ticari hale dönüştürülebilmektedir. Bu ticaretin adı "elektronik ticaret (e-ticaret)"tir.

Elektronik ticaret alışveriş kavramlarını da tekrar düşündürmeye itmiştir. Zira alışverişe gitme, belirsiz, savurgan sözel olarak gezinmeye yönelik bir eylemdir. Sonu açıktır, kesin bir yer ya da plandan yoksundur. Sadece bakınmayı ve hiçbir şey satın almamayı içerebilir. Alışverişe gitmek, haz vericidir ve ölçüsüzdür: çok fazla zaman ya da para harcamayı gerektirebilir. Alışveriş yapmak ise, bir mecburiyeti ya da rutini çağrıştırmaktadır. Burada alışveriş, hem planlı ve hem de sınırlı bir eyleme gönderme yapmaktadır, tanımlanmış bir nesne söz konusudur, sapma yoktur ya da fazladan bir şey satın alma söz konusu değildir. Alışverişe gitmek modaya, kıyafetlere, boş zamana işaret ederken, alışveriş yapmak ise, yiyecek alışverişine ve daha ziyade bir görevin parasına gönderme yapmaktadır. E-ticaret içinde ise; alışverişe gitmek yani boş zaman faaliyetlerin geçirildiği bir süreç ve sonrasındaki süreç yani tam alışveriş ile bütünleşmiştir.

\subsection{Medya (Dergiler ve Web Siteleri) ve Evliliklerin İnşası: Ünlüler Evleniyor!}

E-ticaretin geliştirildiği sanal merkezler sıklıkla web siteleridir. Web siteleri, evlilik endüstrisinin pekiştirilmesinde faydalı araçlar konumundadır. Zira evliliğe dair, gelinlik koleksiyonlarından, modellerine, dügün organizasyonlarından balayı organizasyonlarına dek ayrıntıların verilebildiği ve seçeneklerin tüketiciye alternatifli olarak sunulduğu özgür alanlar durumundadırlar. Örneğin, gelinlik.org sitesinde, "Gelinlik seçimi, Gelinlik güncel, Gelinin iç giyimi, Gelinin ayakkabısı, 2010 gelinlik modelleri" başlıklı konular incelenmektedir.

Web siteleri tüketici ile buluşurlar ve ayrıntılar üzerinden kimi zaman tüketimin gerçekleşmesini sağlamak hususunda etkindirler. Bunun içindir ki, araştırmacı Enginkaya'nın Alışveriş Merkezleri ve Perakendecileri Derneği Dergisi'nden (ARASTA) aktardığına göre (1998), bir web sitesinin tüketicilerle iletişimini etkileyen altı boyut bulunduğu belirtilmektedir. 
Bunlar bilgi, sağduyu, etkileşim, ilişki, özgüllük ve güncelliktir. Buna göre, web üzerinden satış yapmayı düşünen her perakendecinin her bir boyuta eğilmesi gerekmektedir.

- "Bilgi: İnternet üzerinden satışta öncü kuruluşlar sitelerinde araştırma işlevine büyük önem vermektedir. Bu sitelerde bilgiye kolay ve çabuk ulaşılmakta, mevcut stoklardan tavsiye mektuplarına kadar çeşitli veriler sunulmaktadır.

- Sağduyu: başarılı bir sitenin kolay gezilmesi şarttır. Başarılı web perakendecileri, siteleri üzerinde istenen ürüne ulaşılmasını kolaylaştıracak arama işlevleri sunmaktadırlar. Ayrıca sitenin kendisini de bulmak için arama motorlarına ve rehberlere bağlanmalıdır. Perakendecinin sitesinin web içinde, ziyaretçisinin de site içinde kaybolmaması için web sitesinin ziyaretçilerinin genel alışkanlıklarıyla uyum içinde, sağduyuya uygun şekilde işlemesi gerekmektedir.

- Etkileşim: İnternet perakendecilerle tüketiciler arasında iletişim kurduğu ölçüde faydalıdır. İnternet üzerinden alışveriş yapmak isteyenler bilgi formların doldurmaya sicak bakmazlar. Müşteriler hakkında bilgi edinmek isteyen perakendeciler önce ziyaretçilerin demografik dağılımlarını tespit ederler, veri tabanlarını müşterilere daha ayrıntılı bilgi karşılığında imtiyazlar sunarak kademeli olarak geliştirirler. Böylece hem siteye ilgi arttırılmakta, hem müşterilerin tepkileri ölçülmekte, hem de mağazanın reklamı yapılmış olmaktadır.

- İlişki: Sosyal ilişkiler internetin ana temalarındandır. Etkin web siteleri, müşteriyi gerek içeriği, gerekse başka siteler ve sohbet odalarına bağlantıları ile sosyal ilişki olanaklarıyla kuşatmaktadır. Amazon.com ve Barnes\&Noble gibi kitapevleri, müşterilerle ilişkiyi kitap tavsiyeleri, okur değerlendirmeleri ve yazarlarla elektronik sohbet imkânları ile güçlendirmektedir.

- Özgüllükk: boş zaman giderek kıtlaştıkça, tüketiciler internet üzerinde de rastgele gezinmektense vakitlerini daha verimli değerlendirmeye yönelmektedirler. Geleneksel mağazalarda tasarımıla yönlendiren perakendeciler, internette tüketiciyi yönlendirecek araçlara ihtiyaç duymaktadırlar. Perakende sitelerinin müşterilerin özgül ihtiyaçlarına hitap edece esnekliğe getirilmesi gerekmektedir. Ziyaretçilerin kendi zevkine göre ayarladığı "ismarlama" siteler, müşterilerin zamandan tasarruf etmesini sağlamakta ve müşteri memnuniyetini arttırmaktadır. 
A. ÇATALCALI 46

- Güncellik: İnternetin hızlı temposunda siteler gereken bakım ve güncelleştirme yapılmazsa çabuk eskimektedirler. Etkin web siteleri tutarlı, değişmez bir imajla sürekli ve sistemli olarak güncelleşen bilgiyi bir arada sunmalıdır. Özellikle $C D$, yazılım ve kitap gibi kısa yenileme döngülerine sahip ürünlerde güncellik standartları giderek gelişmektedir. İnternet üzerinden satış yapan perakendeci siteler sitelerini düzenli olarak yenileyerek ilgiyi canlı tutmalı, ancak sitenin tasarımında alışkanlığ 1 zedeleyecek değişikliklerden kaçınmalıdır (Arasta, 1998; 55-57).

Özellikle web, interneti ticari olarak daha ilginç hale getirmiştir (Laudon ve Traver, 2009) Web öncesi internet daha çok mesaja dayalı iletişim, dosya transferi ve uzaktan iletişim için kullanılırken günümüzde internetin kullanım alanları öngörülmez bir hızla artmakta ve gelişmektedir (Ayden, Cem \& Özcan Demir, 2011, 150). Örneğin, Mutlugelin.org sitesinde, “Eden Bridals 2009 Gelinlik Modası, Pronovias Gelinlik Modelleri 2009 Koleksiyonu, Pronovias 2012 Gelinlik Koleksiyonu, Çağteks Gelinlik 2012 Koleksiyonu, Akay Gelinlik 2012 Koleksiyonu" başlıklı konular işlenmekte ve koleksiyon tanitımlarının ayrıntılı olarak sanal ortamda yer almasiyla ticaretin hızlandırıldığı söylenebilmektedir.

Türkiye İstatistik Kurumu'nun 2009 yılı araştırması verilerine göre Türkiye'deki hanelerin \%30'unun internet erişimine sahip olduğu ve 16-74 yaş arası bireylerin \% 38'inin internet kullanıcısı sayıldığı belirtilmektedir. Yani kaba bir hesapla Türkiye'deki e-ticaret Pazar hedef kitlesinin 25 milyona ulaşttğını varsayabilir (Ayden, Cem \& Özcan Demir, 2011; 151). Söz konusu internet kullanıcıları evlilik organizasyonlarını düzenleyebilmek ve ayrıntılar üzerinden bilgi alabilmek için bu sitelere ve dergilerin kılavuzluğuna ihtiyaç duymaktadırlar.

Örneğin, yine mutlugelin.org sitesinde ayrıca; "Şapkalı Gelinler, Gelinlik Bakımı, Büyüleyici Gözler İçin Güzellik Önerileri, 2011'in Makyaj Trendleri, Selülitlerinize Pratik Çözümler" başlıklı haberler bulunmaktadır. Gelinlik.org sitesinde ise, "Gelinin Saç Modeli, Gelinin Makyajı, Gelinin Cilt Bakımı, Gelinin Vücut Bakımı, Gelinin Epilasyonu, Gelinin Acil Çantası" haberleri yer almaktadır.

Web sitelerinin ve/veya evlilik dergilerinin sayfaları arasında gezinen tüketiciler, hayal dünyası ve rasyonelite arasında gidip gelmektedirler. Zira tüketiciye sunulan "rüya gelinliklerin vb." gerçek hayatta ödenmesi gereken bir bedeli vardır. Bu bedelin ödenmesinin yanı sıra başka bedellere de rastlanılmaktadır, örneğin; sunulan dünyanın, tüketicinin kendi gerçek dünyası ile ne kadar örtüştüğü gibi. Zira, postmodern bir dünyada imişcesine gezen tüketici için, rasyonalite de 
toplum yapısına göre evlilik türleri ve yapıları bulunmaktadır. Ve onlar, bu yapılara göre hareket içindedirler.

Gelenekler, günümüz modern kent evliliklerinde birtakım değişikliklere uğramıştır. Örneğin "at" artık yerini "gelin arabasına" bırakmıştır. "Koltuğa alma" olarak bilinen törensel motif ise, modern bir hale sokularak, balo salonlarında uygulanan bir adete dönüşmüş, hatta çiftlerin mumlar altından geçerek yaptığ damadın üzerine saçılanlar da artık çerez, şeker vb. değil, madeni ya da kağıt paralar ile parlak kağıttan pullardır. Buna karşılık kırmızı kuşak geleneği değişime uğramadan halen sürdürülmektedir. (Tuna, 2006; 156).

Artık, Modern hedonist, duygulardan ziyade duyumlara yönelik hareket etmektedir. Buradaki temel fikir, hayal etmenin ve fantezilerin, arzuyu yarattığı veya körüklediğidir. Arzu, burada rahatsızlığın eğlenceli bir ifadesi şeklinde görülmektedir. Bu rahatsızlık, arzulanan nesnenin nadiren düşlemiş olduğumuz tatminleri ve doyumları yerine getirmesinden kaynaklanmaktadır. Yükselen duyumlardan eğlenme olană̆ı sağlayan şey ise, arzunun kendisidir. "Arzu-tüketim-arzu" şeklindeki döngü, yeni bir nesneye bağlanma yolu ile tekrar odaklanma tekrar başlamaktadır. Bu anlamda modern tüketim kültürünün tüketicisi yar1-illüzyonist bir doğaya sahiptir (Campbell, 1987; 76, Belk, 1995; 4, Akt: Özcan, 2007; 47). Modern hedonist tüketici karakterinde temel olan şey, tüketiciye haz ve mutluluk sağlayan şeyin, arzulanan tüketim nesnesine erişememe hali olmasıdır. $\mathrm{Ne}$ zamanki bu nesneye erişilirse, nesnenin tüketiciye sağlayacağı haz da yok olmakta ve tüketici, yeni arzu nesnelerinin arayışı içine girmektedir. Asla doyuma ulaşamayan bir tüketici imajı söz konusudur.

Bu noktada fantazyaları destekleyen şeyin bir başka örneğini de görmek mümkündür. Bu da; ünlülerin evlilik merasimlerinin idol özdeşim noktasında buluşulmasıdır. Ünlülerin hayal dügüünlerinin yaratılması ve bu hayal düğüne sahip olmak isteyen tüketicilerin varlı̆̆ı söz konusu iken, evlilik endüstrisi güçlendirilme çabası da artmaktadır. Örneğin, 1981'de resmi bir açklama ile duyurulan ve sonrasında 29 Temmuz 1981 günü St. Paul Kadetrali'nde yapılan törenle dünyaevine giren "Lady Diana ve Galler Prensi Charles'ın" düğününün, hayal dünyasına ilişkin yaratılan en önemli evlilik olduğu söylenebilir. Zira töreni dünyanın her bir köşesinden yaklaşık 1 milyar kişi televizyon ve radyodan takip ederken, 600 bin kişi Buckingham Sarayı'ndan Katedral'a uzanan yol boyunca dizilerek olaya tanık olmuştur (Dinç, 1997; 17). Dolayısıyla Lady Diana'nın giydiği gelinlik ve ayakkabısından, çiçeğinden makyajına, balayını nasıl geçirdiğine ilişkin tüm bilgiler, artık diğer tüketiciler için Pazar içinde hareket eden metalar halindedir. 
Şekil 1 (gelinlik.org-Mayıs-2012)

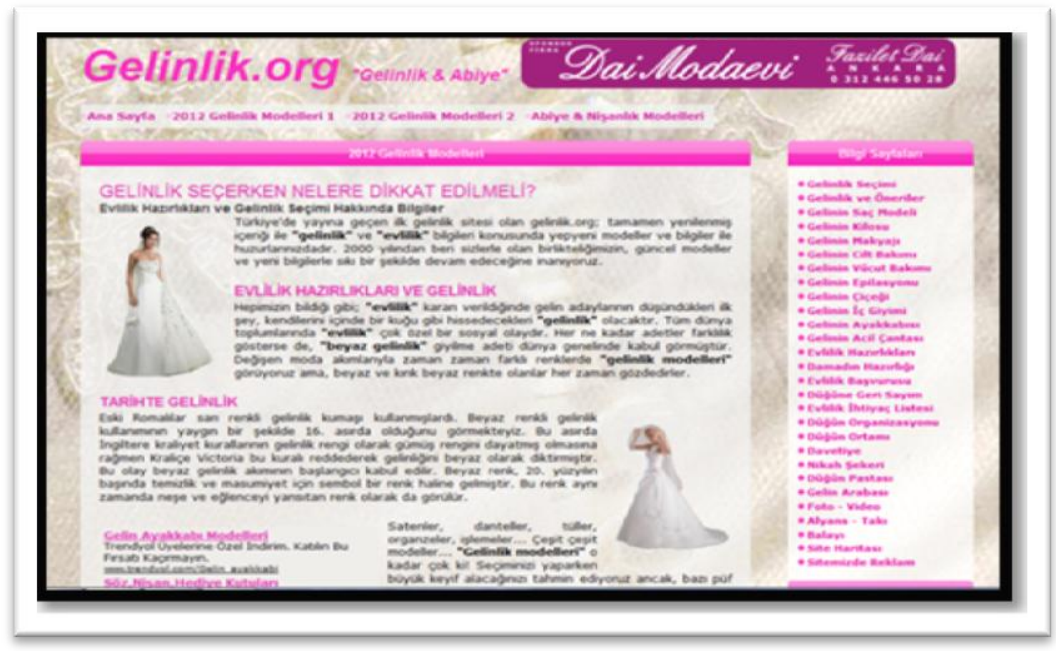

Evlilik hazırlıklarını, hayal dünyasına çekilerek yaşayan tüketicilerin, haz duygusunu ve özdeşim noktalarını bu Pazardan temin etmeleri mümkünken, rasyonalite ile karşılaşmaları daha olasıdır. Örneğin; Gelinlik.org sitesinin (Bknz. Şekil 1) haber içeriklerinde "tarihte gelinlik" konusunun vurgulandığını görmek mümkündür. Bu vurgu, çok eski bir alışkanlığın hatırlatılması ve pazarın canlı tutulmasıyla ilişkisi vardır.

Şekil 2 (mutlugelin.org-Mayıs 2012)

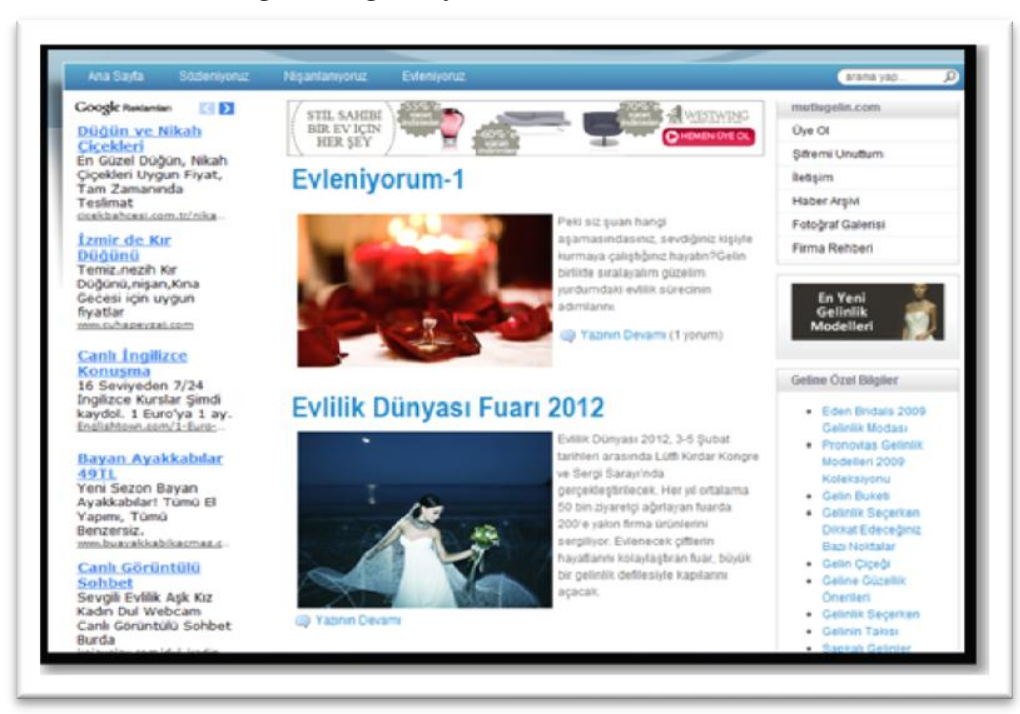


Sosyal Bilimler Dergisi 49

Yine; Mutlugelin.org sitesinin (Bknz. Şekil 2) idol evlilikler ya da ünlü evliliklerine ilişkin içeriklerine bakıldığında ise; "Ünlülerin Düğün Hayalleri", Çiller'in oğluna gizli düğün, En pahalı dügün şarkıcıları, Emre Altuğ Çağla Şikel Evliliği Röportajı, Şöhreti Evlilikleriyle Yakalayanlar" başlıklı haberlere rastlanılmaktadır. Tıpkı Lady Diana örneği gibi, "ünlülerin düğün hayalleri" gündeme alınırken, özdeşim kuran tüketicilerin de bu alana çekildiği anlaşılmaktadır. Emre Altuğ Çağla Şikel Evliliği'nin temel vurgusu da "hayal mutluluk" üzerinedir. Mutlu aşk, mutlu evlilik, iki ünlünün belki de devasa mutluluğuna yapılan vurgu, özdeşim noktasının evlilik-mutluluk stereotipi üzerinde kurulmasını sağlamaktadır.

\subsubsection{Beden, Cinsellik ve Sağlık: Gelin Sağlıklı Olmalı!}

Beden, cinsellik ve sağlık gündeme gelen ve tartışılan konulardandır. Evlilik dergileri ve web sitelerinde de gelin tüketicinin sağlıklı olmasına yapılan vurgu ayrı bir önem taşımaktadır.

Thompson ve Hirshman'a göre, tüketicilerin daha iyi bir vücuda sahip olma çabaları kendilerine verdikleri değer, sosyal ilişkiler içindeki yerleri, yaşam tarzlarının erdemliliği (morality) ve yaşamları üzerindeki kontrolleri ile ilgili anlamlarla ilişkilidir "Bu anlamlar, kültürel idealler ve söylemler, medya, reklam ve tıp söylemlerinden etkilenmektedir. İnce mankenler, zayıflama reçeteleri, kozmetik tavsiyeleri, obezite ve zararları ve benzeri konular her zaman gündemde olan ve çokça tüketilen konulardandır"( 1995; 151, Akt: Dedeoğlu ve Savaşçı, 2005; 79-80).

Günümüzün söz konusu öncelikli bu bakış açısı, Postmodern toplum yapılarında gözlemlenmektedir. Postmodern toplumda "beden" yeni bir alan olarak daha güzel ve daha estetik sunulmak üzere tüketim kültürü içerisindeki yerini almaktadır. "Postmodern toplum içinde, sağlıklı ve güzel görünmekten haz alınacağ1/iyi hissedileceği düşüncesi de, satılabilir bir mal olarak pazarlanır. Dolayısıyla da iyi görünmek ve bedeni korumak, tüketici yaşam şeklinin önemli bir öğesidir" (Nazlı 2006; 9).

Sahip olduğu kapasitesi ile tüketim kültürünün sunduğu şeyleri tüketmeye hazır olan Postmodern beden, adeta bir haz, arzu arayıcısı olarak hareket etmektedir. Bir önceki dönemde dış denetim ve gözetimin nesnesi olan "modern bedenin" tersine postmodern beden, bedenin sahibi tarafından denetlenmekte ve değerlendirilmektedir. Adı geçen bu denetlenme ve değerlendirmenin içinde yine Postmodern bedeni, tüketme kapasitesine uygun halde tutma durumu vardır. Bu görünümün tüketim kültürü içindeki önemli bir örneği, bir haz ve seçkinlik simgesi olarak tasarlanan kadın bedenine ilişkin moda, plastik, kozmetik cerrahi vb. gibi girişim alanlarını ön plana çıkarmaktır (Nazlı, 2006; 10). 
A. ÇATALCALI 50

Baudrillard (1997; 155) bedeni, tüketilen şeyler arasında diğer nesnelerden daha kıymetli, daha eşsiz bir nesne olarak tanımlamaktadır. Dergi içeriklerinde de beden yeniden keşfedilmekte ve özellikle dişil bedenin reklamda, modada, kitle kültüründeki mutlak varlığına dikkat çekilmektedir. "Sağllk, perhiz, tedavi kültürü, gençlik, zariflik, erillik/dişilik, bakım, rejim" gibi kavramlar, bedenin etrafını kuşatarak onu bir kurtuluş nesnesine dönüştürmektedir.

$\mathrm{Bu}$ durumun temelinde, bedenin günümüzde bir kimlik kaynağ olarak öne çıkışı ve bedene ilişkin kodlamaların ön planda yer alması yatmaktadır. Oğuz'a göre, $(2005 ; 31)$ beden imgesi, kitle iletişim araçları ile önemli ölçüde inşa edilmektedir. Ona göre,

"Beden imgesi herkesin sahip olduğu bir şeydir. Genç-yaşlı, kadın-erkek, fakir-zengin herkes beden imgesinden etkilenmektedir. Eğer insanların beden imgeleri toplumun idealleri ile örtüşmezse bir mutsuzluk söz konusu olmaktadır. (...)Bazen bu toplumsal izolasyona, yaşamın değişik alanlarında problemlere, depresyona, gereksiz plastik cerrahiye neden olabilir. İnsanların ruhsal ve bedensel sağlığı için yaklaşımıyla, bu işten belli kazançlar elde eden bir sektör de ortaya çıkmıştır. Düşük kalorili besin maddeleri, yapay şekerler, diyet reçeteleri bu sektöre servetler kazandırmaktadır" (Oğuz, 2005; 31-36).

Yine Baudrillard'a $(1997 ; 71)$ göre de, tüketim toplumlarında güzellik incelikten ayrılamaz ve güzellik, sadece ince ve narinlikle ölçülmektedir. Hatta güzellik aynı anda hem etin yadsınması hem de modanın yüceltilmesi olan modellerin ve mankenlerin profilinde sıska ve etsiz olmasıdır. Fouts ve Burggraf'ın (1999) televizyonda yer alan kadın bedenleri üzerine yaptıkları araştırmalar da, kadının incelik ve cazibe, arzu edilebilirlik, kendine değer verme ve başarı gibi özellikler ile biçimlendirildiklerine işaret etmektedirler. Vartinian ve ark.'da, bu araçların sundukları ince modellerin her zaman popüler olacağını ve var olacaklarını savunmaktadırlar(aktaran: Oğuz, 2005). Bu yaklaşımlardan hareketle kadın bedeninin "üreten" değil, "tüketen" haline dönüştürüldüğü kabul edilmektedir. Zira Bauman'a göre (2000; 227), üreten: üretme kapasitesi ile tüketen ise sadece bedensel ve yaşamsal hazların, deneyimlerin ve duyumların vb. olduğu tüketme kapasitesi ile değerlendirilmektedir.

Örneğin, Mutlugelin.org sitesinde gelin tüketicinin bedenine ilişkin; "Sağlıklı ve Seksi hissetmenin yolları, Adet Döneminiz Tatilinizi Bölmesin, Evlilik Öncesi Cinsel Check-up, Evlilikte İlk Gece Korkusu" başlıklar dikkat çekmektedir. Gelinin kendi bedenini seksi hissetmesinin ya da check-up'tan 
geçmesi gibi konular gelin tüketiciyi Pazar içinde hareket ettirmekte ve bilgilendirmektedir. Gelinlik.org sitesinde ise, "Gelinin Kilosu" adlı konu başlı̆̆

Mutlugelin.org sitesinde aksesuarlara ilişkin de yönlendirmeler bulunmaktadır zira beden bu aksesuarlar ile çekici hale getirilmelidir. "Gelin Buketi, Gelin Çiçeği, Gelinin Takısı, Hangi Gelinliğe Hangi Aksesuar?, Yüzük Ölçüsü" vb. içeriklerde aksesuarın önemli bir araç olduğu vurgusu ön plandadır. Yine Gelinlik.org sitesinde de, "Gelinlik kumaşı ve aksesuar seçimi, Gelinin çiçeği, Alyans - takı" başlıklı haberler ve "gelinlik seçerken nelere dikkat edilmeli?, evlilik hazırlıkları ve gelinlik" haberler beden kullanımını aksesuarla renklendirmek yönünü pekiştirilmektedir.

Şekil 3 (Bride's dergisi içeriği-Mayıs 2012)

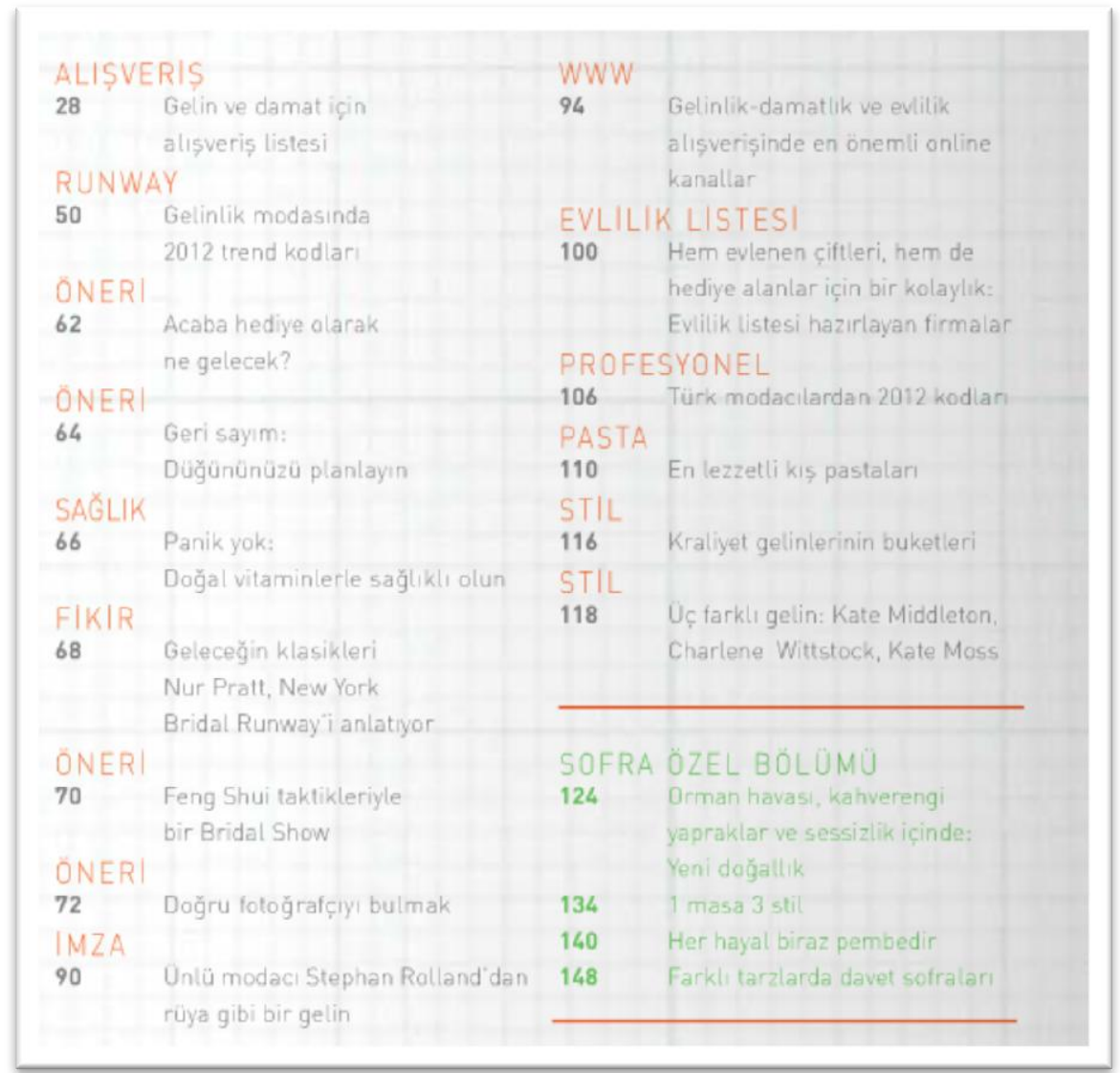


Benzer konuları Bride's dergisinin (Bknz. Şekil 3) içeriklerinde şöyle başlıklarda bulabiliriz; "gelin ve damat için alışveriş listesi, gelinlik modası, geri sayım: Düğününüzü planlayın, doğru fotoğrafçıyı bulmak, hem evlenen çiftleri, hem de hediye alanlar için bir kolaylık: evlilik listesi hazırlayan firmalar, kraliyet gelinlerinin buketleri vb." gibi. Anlaşıldığı üzere, dergi dügün öncesi ve sonrasının tam bir evlilik endüstrisi içinde hareket ettiği perspektifinden yola çıkmaktadır.

Şekil 4 (Perfect Weddings-Mayıs-2012)

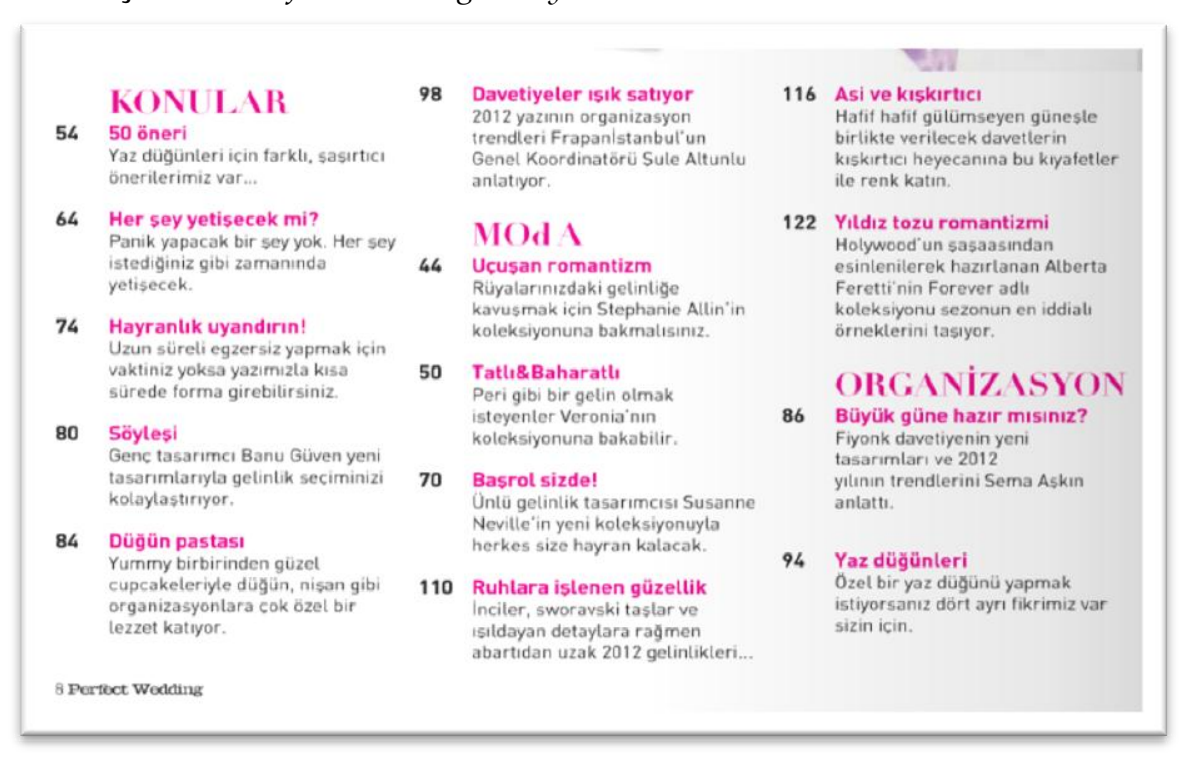

3 ayda bir yayınlanan Perfect Weddings (Bknz. Şekil 4) dergisinde ise, üst başlıklarda yönlendirme söz konusudur; "50 öneri, Herşey yetişecek mi?, Hayranlık uyandırın!, Söyleşi, Düğün Pastası, Uçuşan Romantizm, Başrol sizde!, Ruhlara işlenen güzellik, Asi ve Kışkırtıcı, yıldız tozu romantizmi, büyük güne hazır mısınız? vb. gibi" başlıklarda soru cümleleri ile sorgulama, ünlem cümleleri ile harekete geçirme stratejisi uygulanmaktadır. Romantik bir yaz günü dügün organizasyonu perspektifi ile yola çıan Perfect Weddings dergisinin "konular-moda-organizasyon" temel başlıkları ile ayırdığı içerikler, Pazar içinde hareket edecek tüketicileri yönlendiricidir. 
Şekil 5 (Perfect Weddings kapak-Mayıs 2012 ve Bride's kapak-Mayıs-2012)
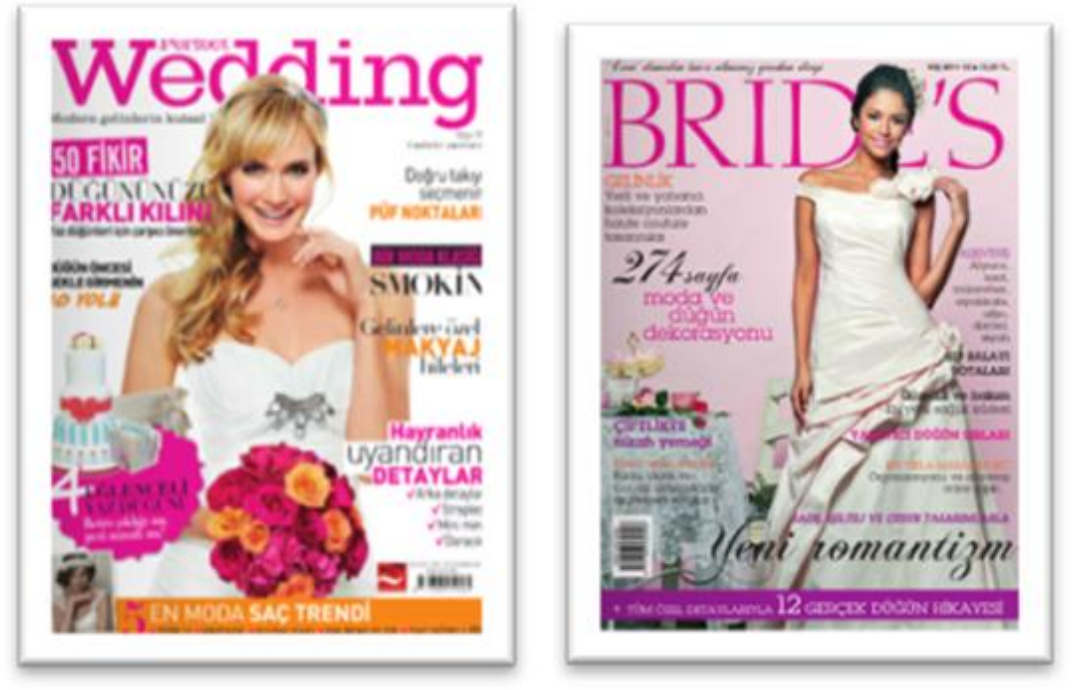

Her iki derginin kapağı incelendiğinde (Bknz. Şekil 5-Şekil 6) ise, hemen hemen ayrı renkleri kullandıkları görülmektedir. Pembe (Siklemen) ve beyazın, eflatun ve sarının kullanıldığı kapak renklerinde, hayal dünyası, rüya ve fantazyalar güçlendirici şekilde sunulmaktadır. Her iki gelin fotoğrafında gösterge olarak gülümsemenin yer aldığ1 ve mutlu olduğu izlenimi ön plana çıkarılmaktadır.

\section{Sonuç}

Sosyal ve Yazılı medya içeriklerinin ardalanı tüketim kültürü ile desteklenmektedir. Tüketim kültürü içinde evlilik endüstrileri de büyük rol oynamaktadır. Araştırmada evlilik dergileri ve evlilik üzerine kurulu web sitelerinde, tüketicilere nasıl ve hangi stratejiler kullanıldığı araştırılmış, ortaya çıkan sonucun göstergeler ve dilin kullanımları doğrultusunda belirleyici olduğu anlaşılmıştır. Medyanın kültürel türdeşliğe yönelik içerikleri, evlilik endüstrilerini de etkilemiş, "evliliğin idealize edilişi" ve "beyaz evlilikler" üzerinden bir tektipleştirme yaratılmaya çalışıldığı görülmüştür. Zira küreselleşme ile birlikte kültür alışverişinin, müzik endüstrisinden filme, giyimden, sağlık endüstrilerine kadar küresel bir Pazar çerçevesinde hareket ettirildiği kabul edilmiştir. Böylesi bir kültür alışverişinin melezlenme doğurduğu gerçektir. Bu nedenle medya 
içeriklerinde "her genç kızın rüyası" olarak süslenen evlilik tipleri öncelikle "beyaz bir gelinlik" sonrasında "organize edilmiş ve hiçbir detay atlanmamış bir evlilik merasimi" ile desteklenerek, tektipleştirilerek idealize edilmeye çalışılmaktadır. Öyle ki, dergilerin üzerinde oluşturulan gelin kimlikleri, "beyaz, masum, temiz ve güzel" göstergeleri doğrultusunda, kadın tüketicilere cazip gelebilmektedir.

Pazar, çizilen sevgili ve evlilik prototipleri hareketlendirilmektedir. Zira medya, "yakışıklı, zengin ve beklenen beyaz atlı prensin varlığı, idol evlilikler vb." içeriklerle tüketicileri hiper-gerçeklik içinde hareket ettirmekte, postmodern bir dünya desteklenmektedir. Sunulan öneriler doğrultusunda örneğin karşı cinse hoş görünmek için güzel kıyafetler satın almak, güzel kokmak, aksesuarlar kullanmak vb. ile tüketim hızlandırılmaktadır. Söz konusu içerikler ayrıca, “aşk, özel yaşam, moda ve güzellik ve pop müzik" şifreleri ile kodlanmaktadır.

Evlilik prototipleri ise, ünlülerin evliliklerinin masalsı yanlarıyla süslenmesi, romantik yaz evliliklerinin, kır düğünlerinin, süslü düğün bahçelerinin ve mükemmel bir organizasyonu hak eden çiftlerin varlı̆̆ düşünceleri ile şekillendirilmektedir. Bireyler, medya içeriklerinde soru ve ünlem cümleleri ile desteklenen dilsel yapı içinde, hak ettiklerine inandıkları evlilik endüstrisine dahil olarak harekete geçirilmektedir.

\section{Kaynakça}

ARASTA, Alışveriş Merkezleri ve Perakendecileri Derneği Dergisi (1998):

“Değişen Tüketici ve 21.yy Perakende Eğilimleri". 14: 50-56.

AYDEN, Cem ve Özcan Demir.(2011). Elektronik Ticaret; Tüketici Davranış ve Tercihleri Üzerine Bir Çalışma. Fırat Üniversitesi Sosyal Bilimler Dergisi. 21(2): 149-161.

AYTAÇ, Ömer.(2006). Tüketimcilik ve Metalaşma Kıskacında Boş Zaman. Kocaeli Üniversitesi Sosyal Bilimler Enstitüsü Dergisi. 11(1): 27-53.

BAUDRILLARD, Jean.(1997). Tüketim Toplumu. Çev. Hazal Deliceçaylı \& Ferda Keskin,

BAUMAN, Zygmunt. (1999). Çalışma Tüketicilik ve Yeni Yoksullar. Çev: Ü. Öktem. İstanbul: Sarmal.

DEDEOĞLU, Ayla Özhan ve İpek Savaşçı. Tüketim Kültüründe Beden Güzelliği ve Yemek Yeme Arzuları: Kadınların Tüketim Pratiklerine Yansımasi. http://eab.ege.edu.tr/pdf/5/C5-S1-2-M9.pdf. Erişim tarihi: 4 Nisan 2012.

DENNING, Michael. (2001). Globalization in Cultural Studies. Sayı: 4(3), Sage Pub. 
ENGINKAYA, E. (2006). Elektronik Perakendecilik ve Elektronik Alışveriş. Ege Akademik Bakış Dergisi. 6(1): 10-16.

FEATHERSTONE, Mike. (1996). Postmodernizm ve Tüketim Kültürü. Çev. M.Küçük. İstanbul: Ayrıntı.

FRAZER E. (1987). Teenage Girls Reading Jackie. Media, Culture and Society, 9.

KÜÇÜKCAN, Ufuk (2002). "Frankfurt Okulu ve Kitle Kültürü Çalışmaları". Kurgu Dergisi. Sayı: 19.

NAZLI, A. (2004), 'Beden ve Tüketim: Tüketim Kültürü İçinde Kadın Bedenine Bir Bakıș'. Sivil Toplum. No:8.

OĞUZ, Işık. (1994). “Değişen Toplum/Mekân Kavrayışları: Mekânın Politikleşmesi, Politikanın Mekânlaşması. Birikim. Toplum ve Bilim Dergisi. 64-65. Güz-Kış.

ÖZCAN, Burcu. (2007). Rasyonel Satın Alma ve Boş Zaman Sürecine Ait Alışveriş Eylemlerinin Birlikte Sergilendikleri Mekanlar: Alışveriş Merkezleri. Sosyal Bilimler Dergisi. Cilt: IX (2): 39-68.

RITZER, George. (1998). Toplumun McDonaldlaştırılması. İstanbul: Ayrintı.

SGROI, Renee. (2006). Consuming The Reality TV Wedding. Ethnologies. 28: 113-131.

TOMLINSON, John. (1999). Kültürel Emperyalizm Eleştirel Bir Giriş. Çev: Emrehan Zeybekoğlu. İstanbul: Ayrıntı Yay.

TUNA, Sibel Turhan. (2006). Türk Dünyasındaki Dügünlerde Koltuklama ve Kırmızı Kuşak Bağlama Geleneği. Bilgi. 38(Yaz): 149-160.

www.elektronikticaretrehberi.com 
A. ÇATALCALI 56 